\title{
LEGO SERIOUS PLAY NO DIREITO ${ }^{1}$ LEGO SERIOUS PLAY IN LAW
}

\author{
Frederico De Andrade Gabrich ${ }^{2}$ \\ Luiza Machado Farhat Benedito ${ }^{3}$
}

\section{RESUMO}

O ensino jurídico não vem acompanhando completamente as significativas mudanças da sociedade no século XXI e isso determina significativa falta de motivação dos alunos. As metodologias de ensino usadas nos cursos jurídicos continuam baseadas na autoridade e saber do professor e dos livros, pautadas no instrucionismo. É preciso o desenvolvimento e a aplicação de novas metodologias de ensino, que favoreçam a mudança do modelo mental dominante, o pensamento sistêmico, a inovação e a solução de problemas reais que motivem os alunos para o aprendizado. O Lego Serious Play cumpre essas funções e precisa ser compreendido e utilizado pelos profissionais Direito.

Palavras-chave: Direito; Metodologias de Ensino Jurídico; Inovação; Lego Serious Play; Construcionismo.

\begin{abstract}
The legal education is not fully following the significant changes in society in the XXI century, and this determines significant lack of student motivation. The teaching methodologies used in legal courses continued to follow the teacher's knowledge and books, grounded in instructionism. It takes the development and application of new teaching methodologies that favor the change of the dominant mental model, systems thinking, innovation and real problems solution that motivate students for learning. The Lego Serious Play fulfills these functions and needs to be understood and used by legal professionals.
\end{abstract}

Keywords: Law; Methodology of Legal Education; Innovation; Lego Serious Play; Constructionism.

\footnotetext{
${ }^{1}$ Os autores agradecem o apoio recebido da Fundação de Amparo à Pesquisa do Estado de Minas Gerais FAPEMIG e da Universidade FUMEC, para realização da pesquisa e divulgação dos seus resultados.

2 Doutor, Mestre e Especialista em Direito Empresarial/Comercial pela UFMG Professor da Universidade FUMEC. Coordenador do projeto de pesquisa Design Instrucional e Inovação das Metodologias de Ensino Jurídico (FAPEMIG). Minas Gerais (Brasil). E-mail: frederico.gabrich@gmail.com

${ }^{3}$ Mestranda e Representante Discente do Programa de Pós-Graduação stricto sensu em Direito da Universidade FUMEC. Pesquisadora no projeto de pesquisa Design Instrucional e Inovação das Metodologias de Ensino Jurídico(FAPEMIG) Advogada. Minas Gerais (Brasil). E-mail: luizafarhatadv@gmail.com
} 


\section{INTRODUÇÃO}

Há entre muitos professores e alunos dos cursos jurídicos um sentimento comum: as metodologias tradicionais usadas no ensino do Direito precisam evoluir muito para garantir não apenas o aprendizado efetivo conectado com as reais necessidades da sociedade, mas também para assegurar mais interesse, envolvimento e motivação.

Certamente, esse cenário decorre do fato de as metodologias tradicionais do ensino jurídico serem praticamente as mesmas desde o século XIX, fortemente marcadas pelo instrucionismo dogmático, pelo saber quase que exclusivo do professor, pela lógica racional e esquemática dos livros e pelo estudo pautado exageradamente no texto da lei.

Em regra (com algumas exceções), as metodologias de ensino usadas nos cursos jurídicos brasileiros desconsideram as significativas mudanças ocorridas na sociedade, especialmente neste século XXI. Tais mudanças refletem diretamente na alteração do perfil médio dos alunos dos cursos de Direito no Brasil, que é resultado do aumento significativo de oferta de cursos jurídicos neste País, mas também e, principalmente, do avanço tecnológico, marcado pela era da informação, que foi cada vez mais difundida a partir do início dos anos 1990, quando a internet começou a se impor como principal plataforma para o fluxo contínuo e crescente da informação.

Essa realidade foi potencializada com a criação de veículos digitais (Google; Youtube; Amazon; iTunes; Facebook; etc) e hoje proporciona a integração (global) na "ponta dos dedos" (principalmente com o surgimento dos smartphones e dos tablets). Tudo isso permitiu (e permite) não apenas o compartilhamento (quase) gratuito e instantâneo de ideias e de informações, mas de entretenimento e de conhecimento.

Os livros impressos, a universidade e o professor, que eram até o início dos anos 1990 as principais referências de informação e de conhecimento, passaram a conviver com a liberdade exponencial de criação, de expressão e de informação permitidas pela internet, pelas redes sociais, pelo Google, pela relativização prática da lógica restritiva da propriedade intelectual.

Diante desse contexto, no âmbito específico do ensino do Direito, as metodologias de ensino precisam não apenas evoluir, mas agregar múltiplas (e novas) experiências e possibilidades de informação, de formação e de encantamento dos alunos, como também mecanismos que promovam a produção de novas ideias que determinem a organização jurídica 
e eficiente dos objetivos e dos problemas reais das pessoas (preferencialmente sem conflitos e sem processos judiciais).

O problema é que a educação jurídica brasileira ainda não é orientada para isso e as metodologias tradicionais usadas no Brasil valorizam quase que exclusivamente o método dedutivo e escolástico, desenvolvido principalmente por meio de aulas teóricas, expositivas, formais (repetitivas e monótonas) e com fundamento significativo na análise do texto expresso da lei. E isso acaba resultando na mitigação do potencial da aprendizagem e intensifica o desinteresse e a dificuldade no ensino dos atuais alunos dos cursos de graduação em Direito.

Esse é o problema que esta pesquisa procura solucionar, por meio da exploração da metodologia Lego Serious Play e de sua combinação com o ensino do Direito em cursos de graduação e de pós-graduação.

Para isso, a pesquisa utiliza-se do método lógico dedutivo e vale-se especialmente do referencial teórico estabelecido por Per Kristiansen e Robert Rasmussen, na obra: Construindo um negócio melhor com a utilização do método Lego Serious Play.

\section{DO INSTRUCIONISMO, CONSTRUTIVISMO E CONSTRUCIONISMO}

A maioria das Instituições e cursos de Direito, sejam elas seculares ou recentes, são marcadas pelo caráter dogmático, rígido e mecânico do ensino dessa Ciência, resultado do culto ao modelo instrucionista da educação.

O instrucionismo consiste na transmissão de conteúdos fundamentalmente por meio de aulas expositivas (monólogos), numa abordagem linear e dogmática, na qual exige-se do aluno a memorização e reprodução do conteúdo repassado pelo professor. Logo, o discente tem um papel passivo (escutar, assimilar e decorar as informações), ao passo que o docente é o polo ativo e o centro da sala de aula.

De acordo com Simone Cristina Mussio, Valéria Cristiane Validório e Véra Maria Ferro Merlini (2014), no modelo instrutivista, o aluno é visto como um sujeito passivo, que apenas recebe as instruções de um professor que transfere o conteúdo por ele adquirido.

Exatamente por isso, Paulo Freire critica esse modelo ao tecer as seguintes considerações:

[...] ensinar não é transferir conteúdo a ninguém, assim como aprender não é memorizar o perfil do conteúdo transferido no discurso vertical do professor. Ensinar e aprender tem que ver com o esforço metodicamente crítico do professor de desvelar a 
compreensão de algo e com o empenho igualmente crítico do aluno de ir entrando como sujeito em aprendizagem, no processo de desvelamento que o professor ou professora deve deflagrar. (FREIRE, 2015, p. 116)

De fato, Freire entende que "ensinar não é transferir conhecimento, mas criar as possibilidades para a sua produção ou a sua construção" (FREIRE, 2015, p. 24).

Para Normam José Solórzano Alfaro, entretanto, a forma tradicional de "ensino do Direito" consiste na transmissão quase unilateral de uma série de estratégias e táticas para o manejo eficiente da linguagem jurídica e do sistema burocrático (ALFARO, 2013, p. 423). Por isso, em muitos casos, quase não há diálogo crítico ou integração entre professor e alunos.

Contudo, é evidente que o instrucionismo é importante para a educação, tanto que ainda é o modelo mais aplicado na maioria das escolas e universidades, o que permitiu o desenvolvimento do conhecimento alcançado pela humanidade até o momento. Porém, o uso excessivo e quase exclusivo desse modelo está desconectado com as inovações, com o fluxo contínuo e livre de informações, bem como com o pluralismo de ideias e de concepções de ensino e de aprendizagem determinados pela era do conhecimento que marca este século.

Per Kristiansen e Robert Rasmussen (2015), sintetizam bem o instrucionismo e demonstram, de maneira simples, a sua importância, mesmo nos dias atuais:

\footnotetext{
Instrucionismo ocorre quando alguém conta o que essa pessoa acha que você deveria saber, e às vezes instrucionismo é a melhor forma. Por exemplo, crianças podem aprender sobre os motivos das luzes de trânsito de duas maneiras. Você pode dizerlhes que verde significa pode ir e vermelho pare, ou você pode mandá-las sair na rua e aprender por experiência. (...) Ele nem sempre é a coisa errada a se fazer; é algo como um remédio potente: se ele vem na hora certa e na dosagem correta, então pode realmente funcionar. (KRISTIANSEN; RASMUSSEN, 2015, p.86)
}

Portanto, não se almeja com esta pesquisa demonstrar que o instrucionismo é uma teoria "morta" e/ou sinônimo de "erro", mas, sim, que é preciso a implementação, a conexão e o aprimoramento de novas teorias e metodologias de ensino. As antigas e novas metodologias de ensino precisam conviver, pois elas não se anulam, mas se complementam.

Nesse sentido, conforme GABRICH (2010) demonstra, os milhares de novos alunos dos cursos de Direito da atualidade são pessoas inseridas em uma realidade completamente diferente daquela vivenciada pelos bacharéis formados nas últimas décadas do século XX. É justamente por conta dessa realidade (e mundo) distinta que é urgente a necessidade da utilização de novas metodologias de ensino, bem como o desenvolvimento de um novo modelo 
mental entre os profissionais do Direito, que valorizem menos o conflito e o processo judicial, em proveito da estruturação jurídica eficiente dos objetivos e dos problemas reais das pessoas.

Não obstante, para instigar o interesse do discente, bem como para deslocar o aluno do polo passivo (de mero receptor de informações e conteúdos) e despertá-lo para o aprendizado, é imprescindível (re)pensar o ensino jurídico, bem como a pesquisa e a implementação de variadas e inovadoras metodologias de ensino. O construtivismo e o construcionismo são teorias importantes para essa evolução.

O construtivismo, desenvolvido por Jean Piaget ${ }^{4}$, busca entender o processo de aprendizagem do indivíduo; estuda o papel ativo do sujeito na construção dos novos conhecimentos. O construtivismo busca conectar o sujeito cognoscente à unidade complexa pluridimensional na qual ele está inserido (a sua realidade), nos planos racional, afetivo e relacional.

Entre os aspectos mais marcantes da teoria epistemológica genética de Piaget, está a certeza de que o conhecimento é construído quando quem aprende interage com o objeto que será apreendido. Assim, a relação entre sujeito e objeto, oferecida por Piaget, determina uma atitude ativa de quem aprende, revelando a necessidade de uma postura avessa à passividade no processo de aprendizagem.

O construtivismo (de Piaget) fundamentou-se na pesquisa dos estágios de desenvolvimento infantil e sua importante conclusão (resultado) foi a de que crianças não adquirem simplesmente conhecimento pouco ao pouco, mas sim com suas interações no mundo. Sobre o tema, KRISTIANSEN e RASMUSSEN (2015) enfatizam que as crianças usam sua experiência no mundo para construir quadros coerentes e robustos chamados “estruturas do pensamento”. As crianças não são apenas passivos absorvedores de experiências e informações, mas construtores ativos de teorias. Ou seja, o conhecimento é uma elaboração contínua e que não pode ser simplesmente imposta, precisa ser experimentada e vivenciada.

Nesse sentido, segundo Fernando Becker:

\footnotetext{
4 Jean William Fritz Piaget, suíço nascido em 1896, biólogo e psicólogo, foi considerado o "pai" do construtivismo. Piaget foi um epistemólogo, considerado um dos mais importantes pensadores do século XX. Defendeu uma abordagem interdisciplinar para a investigação epistemológica e fundou a Epistemologia Genética, teoria do conhecimento com base no estudo da gênese psicológica do pensamento humano. Disponível em: https://pt.wikipedia.org/wiki/Jean_Piaget. Acesso em 13 de ago. 2016.
} 
"Construtivismo significa isto: a ideia de que nada, a rigor, está pronto, acabado e de que, especificamente, o conhecimento não é um dado, em nenhuma instância, como algo terminado. Ele constitui pela interação do indivíduo com o meio físico e social, com o simbolismo humano, com o mundo das relações sociais; e se constitui por força de sua ação e não por qualquer outra dotação prévia, na bagagem hereditária ou no meio, de tal modo que podemos afirmar que antes da ação não há psiquismo nem consciência e, muito menos, pensamento." (BECKER, 1993, p. 88-89)

O construtivismo propõe que crianças (mas isso se aplica a qualquer pessoa, inclusive adultos, em processo inicial de algum aprendizado) não são simplesmente, como bem sintetizou KRISTIANSEN (2015, p. 84), recipientes vazios onde se pode colocar conhecimento. Ao contrário, elas são criadoras de teorias que constroem e rearranjam este conhecimento baseado no que elas já sabem e experimentaram.

De fato, para alguns autores, o construtivismo pode e deve influenciar métodos educacionais em todos os níveis de escolaridade. Nesse sentido, para Sanny A. da ROSA (1994, p.32 e segs.), existem no construtivismo piagetiano as possibilidades necessárias para a efetiva mudança da escola brasileira, e defende que "se há algo novo no ar que se respira, de modo mais intenso há mais ou menos uma década, esse novo tem um nome: chama-se construtivismo". A partir desse "novo", a autora contrapõe o construtivismo aos métodos tradicionais (monótonos e centrados no saber dos professores e livros), para redefinir o papel do docente e para superar as principais resistências às mudanças em sala de aula: apego ao método, à rotina e à autoridade.

Nesse sentido, para ROSA (1994):

A ação pedagógica envolve dois pólos: o ensino e a aprendizagem, representados, respectivamente, pelo professor e pelo aluno. Os teóricos construtivistas não têm, em princípio, como preocupação científica pensar o pólo 'ensino' e sim, o pólo 'aprendizagem'. De modo mais preciso, não estão voltados à questão do 'como ensinar', mas ao 'como o indivíduo aprende'. (ROSA, 1994, p.40)

Realmente, pesquisar e compreender como o indivíduo aprende é medida elementar para o sucesso do ensino. E isso é importante nesta pesquisa, principalmente, em virtude do quadro atual de desinteresse, de apatia e de passividade de parte significativa dos atuais discentes de cursos jurídicos. Porém, é preciso atentar-se, também, para as formas de como se ensinar, pois a educação é uma via de mão dupla. 
Há autores que definem a pesquisa do construtivismo com enfoque no ensino e na aprendizagem como o "construtivismo em nova dimensão", baseando-se nas concepções de Lev VYGOTSKY, César COLL e Berta BRASLAVSKY, na qual, valorizam-se os papéis respectivos do aluno e do professor na 'construção progressiva de significados', compartilhada na aprendizagem e no ensino. Nesse caso, privilegiam-se as dimensões sociais da didática (ensino e aprendizagem; professor e aluno; forma e conteúdo). (BRASLAVSKY, 1993)

César Coll ensina que a educação escolar ideal não é a que transmite os saberes constituídos e legitimados socialmente, mas aquela que assegura condições ótimas para o aluno desenvolver suas capacidades cognitivas, afetivas, sociais e de aprendizagem. (COLL, 1992, p. 11). Além disso, o mesmo autor reforça a:

importância da criatividade e da descoberta na aprendizagem, ao atribuir à atividade do aluno um papel decisivo na aprendizagem, a minimizar e relativizar a importância dos conteúdos e a conceber o professor mais como um guia, um facilitador ou um orientador da aprendizagem do que um transmissor do saber constituído. (COLL, 1992, p. 11)

E foi justamente nessa busca pela conexão e aprimoramento do construtivismo com as áreas de teorias do aprendizado e educação, que Seymour Papert (colega de Piaget no fim dos anos 1950 e início dos 1960) desenvolveu a teoria do construcionismo.

De fato, pode se dizer que o construcionismo é uma extensão ou uma evolução do construtivismo. Papert buscou criar um ambiente mais favorável às teorias de Piaget, bem como ampliou os destinatários da pesquisa, ultrapassou o universo do ensino infantil e preocupou-se, também, com a educação dos adultos. Nesse sentido:

Embora ambos, Piaget e Papert, tenham desenvolvido suas teorias através da observação do comportamento e atividades das crianças, Papert, especialmente, acreditava que esses resultados eram igualmente aplicáveis aos adultos.

(...)

Ele (Papert) procurou criar um ambiente de aprendizagem que fosse mais propício para as teorias de Piaget. Ele (Papert) percebeu que os ambientes escolares convencionais eram muito estéreis, muito passivos, muito dominados pela instrução. Tais ambientes não permitiam que as crianças fossem construtoras ativas, e ele sabia que elas eram. (LEGO Group. The science of lego serious play. 2002, p.8-9. Disponível em: www.seriousplay.com) Tradução livre ${ }^{6}$

\footnotetext{
5 Sobre o tema recomenda-se a leitura do artigo científico Construtivismo e Currículo, de autoria de Odair Sass . Disponível em: http://www.crmariocovas.sp.gov.br/pdf/ideias_26_p087-103_c.pdf . Acesso em: 11 mar. 2016.

${ }^{6}$ Although both Piaget and Papert developed their theories through observing the behavior and learning activities of children, Papert, especially, believes that these findings are equally applicable to adults.

(...)

He wanted to create a learning environment that was more conducive to Piaget's theories. He saw conventional school environments as too sterile, too passive, too dominated by instruction. Such environments did not allow
} 
KRISTIANSEN e RASMUSSEN (2015, p.84) explicam que Papert enxergava os ambientes escolares convencionais como muito estéreis, passivos e dominados pela instrução; eles não providenciavam nem promoviam uma atmosfera que permitia às crianças serem construtoras ativas (algo que ele sabia que elas eram). Por isso, segundo KRISTIANSEN e RASMUSSEN:

\begin{abstract}
Se acreditarmos que retemos conhecimento como estruturas baseadas em nossa interação com o mundo, então nós podemos criar conhecimento mais rápido e melhor (aprendizado) quando estamos engajados na construção de um produto ou algo externo. Resumidamente: "Quando você cria no mundo você constrói na sua mente". (...) Quando pessoas constroem coisas no mundo, elas simultaneamente juntam teorias e estruturas de conhecimento em suas mentes. Então esse novo conhecimento permitelhes construir coisas ainda mais sofisticadas mundo afora, o que rende ainda mais conhecimento, e assim por diante, em um ciclo que se reforça a si próprio. Isso respalda um princípio central do método LEGO Serious Play: aprendizado acontece especialmente quando criamos ativamente algo físico/concreto que é externo à nós. (KRISTIANSEN; RASMUSSEN, 2015, p.85)
\end{abstract}

Papert, professor de matemática, observou que as aulas de sua disciplina eram monótonas, entediantes, sem engajamento, passivas e dominadas por instrução; ao passo que nas aulas de arte era evidente o engajamento, o entusiasmo e a colaboração dos alunos, pois as aulas eram marcadas pela criatividade, pela participação e pela originalidade, com o sentimento absoluto de diversão e prazer. Tal contexto o levou a planejar uma abordagem mais construtiva para a matemática (que também poderia ser uma aula empolgante, maravilhosa, desafiadora, engajadora e tão criativa quanto às aulas de arte). (KRISTIANSEN; RASMUSSEN, 2015, p.85)

Daí, então, o principal propósito do construcionismo de Papert; criar ambientes e possibilidades que estimulem o interesse e a participação ativa dos alunos (em qualquer disciplina e Ciência), instigando os sentidos e aguçando a criatividade, bem como a integração e a afetividade, tanto dos discentes, quanto dos docentes.

No caso específico de Papert, ele chegou a desenvolver, nos anos 1970, uma linguagem de programação de computadores chamada Logo, que tornava possível às crianças aprenderem matemática construindo ilustrações, animações, músicas, jogos e simulações (dentre outras coisas) no computador. Em meados dos anos 1980, membros de sua equipe no MIT (Instituto de Tecnologia de Massachussetts) desenvolveram o LEGO TC Logo, o que

children to be the active builders that he knew they were. (LEGO Group. The science of lego serious play. 2002, p.8-9.) Disponível em: www.seriousplay.com 
reuniu a linguagem de computador com os familiares blocos LEGO. Essa nova ferramenta permitiu às crianças controlarem suas estruturas de LEGO criando programas no computador. Tal experiência levou Papert a concluir: "Melhor aprendizado não virá de achar modos melhores do professor ensinar, mas dando ao aprendiz melhores oportunidades em construir". (KRISTIANSEN; RASMUSSEN, 2015, p.86)

Assim, o fio condutor essencial do método de aprendizado LEGO SERIOUS PLAY é o conceito de construcionismo. E isso fica evidente quando KRISTIANSEN E RASMUSSEN afirmam o seguinte:

Aprender construindo algo que você possa identificar e ter orgulho, e sobre o que você possa pensar: "é nisso que eu sou bom". Como Papert mesmo realçou: "O que aprendemos no processo de construir coisas que nós gostamos penetra muito mais profundamente em nosso subconsciente do que aquilo que qualquer um pode nos dizer”. (KRISTIANSEN; RASMUSSEN, 2015, p.86)

O método LEGO Serious Play, centrado no construcionismo, evidencia, assim, a necessidade da educação pautada no equilíbrio entre a razão e a emoção; na participação ativa do aluno, bem como no desenvolvimento do pensamento sistêmico (holístico), não linear e marcadamente emocional, que auxilia o desbloqueio de novos conhecimentos e, assim, proporciona um aprendizado efetivo.

Tais características são imprescindíveis para o ensino, como será demonstrado.

\section{A NECESSIDADE DA EDUCAÇÃO BASEADA NA RAZÃO E NA EMOÇÃo}

Um ponto relevante da educação é não limitar o ensino. KRISTIANSEN e RASMUSSEN (2015) definiram, acertadamente, que o propósito é explorar e aprender, em vez de apenas ensinar. O ensino precisa ser motivador, despertar curiosidade e sentidos. É necessário experimentar o conhecimento, não apenas dizê-lo e/ou escutá-lo.

Nesse sentido, segundo Edgar Morin:

É impressionante que a educação que visa a transmitir conhecimentos seja cega quanto ao que é o conhecimento humano, seus dispositivos, suas enfermidades, suas dificuldades, suas tendências ao erro e à ilusão, e não se preocupe em fazer conhecer o que é conhecer. (MORIN, 2013)

Assim como o filósofo Edgar Morin, Rubem Alves aponta a necessidade de um ensino pautado na razão e na emoção, com foco no desenvolvimento do ser humano. A emoção e a inteligência estão interligadas (ALVES, 2014, p.20). Rubem Alves esclarece, ainda, que: os 
conhecimentos da ciência são importantes. Eles nos dão poder. Mas eles não mudam o jeito se ser das pessoas. (ALVES, 2013, p.40) A mudança de comportamento ocorrerá por intermédio da emoção e da experiência, pois não basta apenas dizer o que se deve/espera transformar, é preciso vivenciar a transformação e/ou o que a impulsiona.

A mecanização e massificação do ensino, cada vez mais verticalizado e realizado sem observar a necessidade da inter, da multi e da transdisciplinaridade, distanciam o homem do ser humano, da transformação pessoal que o ensino é capaz de proporcionar. Como disse, acertadamente, Edgar Morin (2013, p.43): a educação do futuro deverá ser o ensino primeiro e universal, centrado na condição humana. E mais:

[...] o século XX produziu avanços gigantescos em todas as áreas do conhecimento científico, assim como em todos os campos da técnica. Ao mesmo tempo, produziu nova cegueira para os problemas globais, fundamentais e complexos, e esta cegueira gerou inúmeros erros e ilusões, a começar por parte dos cientistas, técnicos e especialistas. (MORIN, 2013, p.42)

Morin evidencia ainda, que:

[...] no mundo humano, o desenvolvimento da inteligência é inseparável do mundo da afetividade, isto é, da curiosidade, da paixão, que por sua vez, são a mola da pesquisa filosófica ou científica. A afetividade pode asfixiar o conhecimento, mas pode também fortalecê-lo. Há estreita relação entre inteligência e afetividade: a faculdade de raciocinar pode ser diminuída, ou mesmo destruída, pelo déficit de emoção; o enfraquecimento da capacidade de reagir emocionalmente pode mesmo estar na raiz de comportamentos irracionais. (MORIN, 2013, p.20)

Não obstante, segundo ALVES:

O nascimento do pensamento é igual ao nascimento de uma criança: tudo começa com um ato de amor. Uma semente há de ser depositada no ventre vazio. E a semente do pensamento é o sonho. Por isso os educadores, antes de serem especialistas em ferramentas do saber, deveriam ser especialistas em amor: intérpretes de sonhos. (ALVES, Rubem. A alegria de ensinar. 2000)

Assim, o conhecimento humano acontece e é maximizado exatamente quando se obtém a combinação exata entre razão e sensibilidade, o justo meio entre o raciocínio lógico abstrato e a emoção da vida, da prática. Não há como desconsiderar que o ser humano pensa, se comunica, ensina e aprende por meio da combinação entre imagens e palavras; razão e emoção. 
Logo, o ensino formal do Direito ou de qualquer outra ciência precisa ser desenvolvido com a combinação entre a razão e a emoção (binômio basilar do construcionismo e do método $L E G O$ Serious Play).

Inquestionável, assim, que o ensino do século XXI precisa de uma (r)evolução, a fim de resgatar a condição humana e ser capaz de eliminar as cegueiras sociais. Mas, além da necessidade de mudança das metodologias de ensino jurídico e do modo de aprendizagem, é imprescindível, no ensino do Direito, a mudança do modelo mental dominante (fortemente instrucionista, dogmático, pautado na letra da lei e no culto ao processo e conflito).

Para facilitar a mudança do modelo de pensamento ainda dominante no Direito, Frederico Gabrich propõe a Análise Estratégica do Direito (GABRICH, 2010).

De acordo com essa teoria, o Direito existe para estruturar sistematicamente os objetivos das pessoas, para que eles sejam realizados com a maior eficiência possível, com a maior satisfação e felicidade possíveis de todas as pessoas envolvidas direta ou indiretamente. A Análise Estratégica do Direito tem como base o pensamento sistêmico (holístico) e afirma que o Direito deve ser compreendido como uma das (muitas) ciências usadas pelas pessoas (naturais e jurídicas) para a estruturação eficiente dos seus objetivos (com o menor desgaste psicológico, de tempo e de dinheiro possíveis), preferencialmente sem conflitos, com a máxima felicidade e, certamente, sem os pressupostos do processo judicial e/ou da solução não consensual de eventuais divergências que decorrem (naturalmente) do relacionamento humano. De acordo com esse paradigma, se a estruturação jurídica for bem realizada, não haverá conflito, não haverá processo judicial e, no plano ideal (utópico), não haverá infelicidade.

Em outras palavras, repita-se, de acordo com a perspectiva da Análise Estratégica do Direito, no plano absolutamente ideal, se existe conflito e/ou se existe a necessidade de um processo judicial para dirimi-lo, há um importante indicativo de falha no planejamento jurídico dos objetivos das pessoas (naturais e jurídicas) envolvidas no caso.

É preciso, todavia, que a mudança de paradigma e de modelo mental comecem no plano teórico e prático, a partir também das metodologias de ensino utilizadas no ensino jurídico. E a combinação das metodologias tradicionais, com o uso de outras mais inovadoras, como é o caso do LEGO Serious Play, certamente podem representar um excelente caminho nessa direção, especialmente porque valorizam a identificação e realização mais eficiente dos objetivos das pessoas, com o desenvolvimento de soluções sistêmicas e sustentáveis dos problemas reais, com amparo na razão e no afeto. 


\section{LEGO Serious Play (LSP)}

O método LEGO Serious Play foi desenvolvido pela empresa dinamarquesa LEGO, para desbloquear novos conhecimentos, e nasceu do desejo humano de fazer e criar coisas, bem como da busca pela geração valor para as pessoas.

Os criadores do método perceberam que para maximizar o potencial humano é preciso desenvolver um pensamento estratégico, aguçar a criatividade, a imaginação e os sentidos, permitindo, assim, um pensamento inovador.

Inicialmente desenvolvido para auxiliar o desenvolvimento de estratégias empresariais e a tomada de decisões nas organizações, o LSP sempre teve em sua essência a criatividade e a imaginação. De fato, no início dos anos 1990, Robert Rasmussen começou a investigar como poderia aplicar os seus conhecimentos sobre como crianças aprendem e daí elaborar algo para que os adultos pudessem desenvolver estratégias. Em 2001 o LSP teve sua primeira versão como uma "técnica de pensamento, comunicação e resolução de problemas para grupos" e se disseminou pelo mundo, com inúmeros aprendizados e rearranjos, sendo significativamente mais sofisticado hoje e aplicado em diversos segmentos, inclusive o educacional.

O desenvolvimento da metodologia LEGO Serious Play acabou demonstrando que é preciso engajar as pessoas (alunos) e permitir que todas $(100 \%)^{7}$ participem dos processos de construção do conhecimento e das atividades, pois só assim é possível elevar o rendimento da equipe (sala de aula) e o nível de compreensão de cada conteúdo.

Para isso, é preciso criar um ambiente que permita que pessoas (alunos) estejam engajadas, estimuladas, com liberdade para criar, para inovar (e inclusive errar) e para conseguir expelir, inclusive, o que elas não sabem que sabem, pois, como afirma Rasmussen (2015, p.18): as próprias pessoas normalmente sequer sabem o que elas sabem.

De fato, a metodologia do LEGO Serious Play, extremamente motivacional e participativa, baseada no construcionismo de Papert, combate os desafios atuais relacionados com o desinteresse dos alunos pelas aulas marcadamente expositivas e instrutivistas (que ainda prevalecem, infelizmente, no ensino jurídico). A metodologia proporciona agregação e participação dos alunos e professores, pois todos são importantes, podem e sabem contribuir

\footnotetext{
${ }^{7}$ Os criadores do método LSP buscavam alternativas para eliminar as famosas e frequentes "Reuniões 20/80", que são aquelas onde $20 \%$ dos presentes se expressam e $80 \%$ ficam calados. Fato muito comum nas salas de aulas dos cursos jurídicos do Brasil.
} 
para o processo de ensino e de aprendizagem. Além disso, o LEGO Serious Play potencializa insights (ideias novas, às vezes desconhecidas dos próprios participantes e que são expelidas subitamente durante o desenvolvimento das atividades), aumenta a confiança e o comprometimento de todos os sujeitos do processo de educação, pois permite a vivência e a experiência do conhecimento. (KRISTIANSEN; RASMUSSEN, 2015, p.23)

Basicamente, a metodologia do LEGO Serious Play é desenvolvida com uso de metáforas (que podem gerar maneiras radicalmente novas de entender as coisas, pelo seu papel ativo, construtivo e criativo na cognição humana) e com fundamento na empatia (que permite aos participantes se colocarem no lugar das pessoas envolvidas com o tema-problema apresentado pelo professor, facilitando a construção de soluções inovadoras e possíveis).

LEGO Serious Play não é um brinquedo, mas uma metodologia voltada para geração de ideias, para a inovação, para o conhecimento e para a aprendizagem baseada na construção literal de modelos palpáveis que representem a efetiva solução dos problemas reais das pessoas. A metodologia pressupõe que as pessoas são mais inovadoras e aprendem mais quando "pensam com as mãos" e constroem a solução de problemas relacionados realmente com as suas vidas. LEGO Serious Play ${ }^{8}$ é uma metodologia com propósito explícito e específico que auxilia em construções que gerem reflexões e experiência pessoal.

Além de estar baseada no construcionismo que, como supracitado, foi desenvolvido por Seymour Papert, a metodologia do LEGO Serious Play tem também como pressuposto o PBL (Problem-Based Learning), ou aprendizagem baseada em problemas.

De fato, a aprendizagem baseada em problemas é conhecida mundialmente como uma metodologia de ensino-aprendizagem caracterizada pelo uso de problemas da vida real para estimular o desenvolvimento do pensamento crítico e das habilidades de solução de problemas

\footnotetext{
${ }^{8}$ Serious Play é um "jogo sério" tem um propósito explícito e acontece de forma específica. Este propósito é tratar um assunto real com os participantes ao redor de uma mesa por meio do engajamento deles, desbloqueio de seus conhecimentos e quebra do pensamento convencional. Como explicam KRISTIANSEN e RASMUSSEN (2015, p.41): Os participantes sabem que utilizarão sua imaginação - isto é, sua habilidade para formar uma imagem mental de algo que ainda não existe - para antecipar coisas que ainda não aconteceram. Eles estão explorando um estado plausivel e possível ou vendo a realidade atual de uma maneira diferente além de entender sua complexidade e incerteza de forma diferente. Ou seja, permite que os participantes (alunos) desenvolvam o seu senso-crítico e pensem de maneira divergente, "fora da caixa". Os participantes se engajam no jogo para aprender, gerar opções e desenvolver um novo entendimento juntos. Realizam um processo que os prepara para tomarem decisões melhores, e isto alinha seus objetivos e pontos de ação e gera novos aprendizados. $\mathrm{O}$ desafio e capacidade de imaginação que o método LSP e o próprio jogo propiciam ajuda a quebrar o padrão de pensamento e encoraja os envolvidos a utilizar livremente sua imaginação.

O LSP é uma abordagem de pensamento, comunicação e resolução de problemas para tópicos que são reais para os participantes, sendo uma preparação dos sujeitos para o sucesso. (KRISTIANSEN e RASMUSSEN, 2015, p.42-46).
} 
e a aquisição de conceitos fundamentais da área de conhecimento em questão. (RIBEIRO, 2008).

O PBL originou-se na escola de Medicina da Universidade de McMaster (Canadá) no final dos anos 1960, inspirado no método de casos de ensino da escola de Direito da Universidade de Harvard (USA), justamente em resposta à insatisfação e ao tedio dos alunos frente ao grande volume de conhecimentos percebidos como irrelevantes à prática médica (o que é comum na educação de outros cursos, inclusive o de Direito). (RIBEIRO, 2008).

O PBL é uma metodologia de ensino que busca uma formação que integre a teoria à pratica, bem como o mundo acadêmico ao mercado de trabalho, promovendo o desenvolvimento de habilidades e atitudes profissionais e cidadãs.

Segundo RIBEIRO (2008) a principal característica do PBL é que o método utiliza um problema para iniciar, direcionar, motivar e focar a aprendizagem, diferentemente das demais metodologias convencionais que utilizam problemas de aplicação apenas ao final de conteúdos.

Trata-se de uma metodologia colaborativa, construtivista e contextualizada, na qual situações-problema são utilizadas para iniciar, direcionar e motivar a aprendizagem de conceitos, teorias e o desenvolvimento de habilidades e atitudes no contexto da sala de aula.

A aprendizagem baseada em problemas promove, assim, o ensino significativo de conhecimentos, proporcionando uma aprendizagem ativa, centrada nos discentes e que contempla o trabalho de grupos pequenos de alunos que são facilitados por tutores (o professor é um facilitador do processo de aprendizagem).

O LEGO Serious Play apresenta e se utiliza dessas características e diferenciais do PBL, para promover o aprendizado ativo, significativo, crítico criativo, estratégico e efetivo. Nesse sentido, é importante observar que o LEGO Serious Play utiliza situações-problema (PBL) no inicio do processo desenvolvido em cada sessão/aula, para instigar a criatividade e desafiar os participantes/alunos na elaboração de soluções e de respostas concretas, construídas a partir das peças de LEGO, em três dimensões.

Para isso, preferencialmente, os participantes devem possuir conhecimento mínimo acerca do tema-problema, para que tenham melhores condições para o desenvolvimento das soluções que o problema colocado requer. E isso pode ser obtido por meio de textos, livros e vídeos disponibilizados pelo professor antes do uso da metodologia, caso o tema-problema não tenha correlação direta com os conhecimentos e experiências pretéritas dos participantes. 
Antes do início e da distribuição das peças de LEGO, o professor deve dividir a turma em grupos de quatro a cinco pessoas, e deve demonstrar a "etiqueta" da metodologia $L E G O$ Serious Play, segundo a qual, em virtude do uso de metáforas e da empatia, todos devem participar e saber que não existem respostas absolutamente certas ou erradas para os problemas apresentados, mas apenas respostas significativas, que devem ser interpretadas e discutidas pelos alunos.

Formados os grupos, o professor deve, primeiro, desenvolver uma atividade para que os participantes conheçam as peças LEGO e possa interagir com elas, como, por exemplo, atribuir um tempo para que os participantes individualmente construam a maior torre possível, ou para que representem com as peças as suas histórias pessoais mais significativas ou curiosas, para que sejam apresentadas para o grupo e para os demais alunos.

Em seguida, o professor deve apresentar o(s) tema(s)-problema(s) para os grupos (que pode ser um único ou vários que tenham interconexão) e pedir, primeiro, que os participantes construam com as peças LEGO as suas soluções individuais, para que sejam apresentadas em seus próprios grupos.

Na sequência, a partir das respostas individuais e debates decorrentes, o professor deve solicitar ao grupo que desenvolva outro modelo com as peças de LEGO, que represente uma solução decorrente do entendimento do grupo.

No final, especialmente quando os problemas dos grupos não são idênticos, mas interconectados, o professor deve solicitar que os grupos encontrem e desenvolvam as conexões entre os modelos criados em cada grupo, de maneira a evidenciar a importância das soluções sistêmicas, holísticas e sustentáveis.

\subsection{LEGO Serious Play (LSP) NO ENSINO JURIDICO}

O ensino e a prática jurídica brasileira, indiscutivelmente, passam por uma crise que pode ser analisada a partir de diversos aspectos ideológicos, sociais, culturais, econômicos, políticos e metodológicos, sendo que a esta pesquisa, por conta de um corte epistemológico, somente interessam os aspectos metodológicos.

Segundo Peter Senge, "nossos modelos mentais determinam não apenas a forma como entendemos o mundo, mas também como agimos.” (SENGE, 2008, p. 201). 
Nesse sentido, o ensino e a prática jurídica brasileiras são desenvolvidas, quase sempre, a partir de uma mesma forma de pensar, de um modelo mental dominante e já destacado acima. Contudo, o aprendizado efetivo e pleno ocorre quando há não apenas razão e conteúdo, mas emoção e criatividade.

Nesse sentido, como Buzan também esclarece:

As pesquisas mostram que o cérebro é um órgão multidimensional, capaz de absorver, interpretar e recuperar informações por meio de recursos que são muito mais sensitivos, criativos, multifacetados e instantâneos do que as palavras escritas e faladas. A mente é capaz de entender uma informação não-linear, pois é projetada para essa função. E ela faz isso o tempo todo, seja quando vemos fotografias e figuras, seja quando interpretamos outras imagens que estão ao nosso redor.

Quando o cérebro ouve uma série de frases, ele não absorve a informação palavra a palavra, linha a linha - ele a considera como um todo. Ele a classifica, interpreta e assimila de diversas maneiras. Ouvimos as palavras e as situamos no contexto do conhecimento que já possuímos. Não temos necessidade de escutar todo um conjunto de frases antes de elaborarmos uma resposta. (BUZAN, 2009, p. 17-18)

De fato, como Buzan observa (2009, p.22), é preciso saber mais sobre como o cérebro recebe, processa, analisa, retém (armazena) e recupera informações, pois isso é absolutamente fundamental tanto para a criação, para o compartilhamento e para o desenvolvimento das ideias, quanto para o desenvolvimento de metodologias de ensino e aprendizagem, entre as quais podem ser destacados, o LEGO Serious Play.

Nesse sentido, o cérebro, para Buzan:

“[...] não raciocina de forma linear e monótona. Ao contrário, ele pensa em várias direções ao mesmo tempo - partindo de ativadores centrais presentes em Imagenschave ou em Palavras-chave. Chamo isso de Pensamento Radiante. Como o termo sugere, os pensamentos se irradiam de dentro para fora, como os galhos de uma árvore, as nervuras de uma folha ou os vasos sanguíneos, que se propagam a partir do coração. " (BUZAN, 2009, p. 22)

Ademais, o cérebro trabalha melhor com as mãos, e existe uma evidencia ${ }^{9}$ bem fundamentada sobre a profunda interdependência entre a mão e o cérebro, sendo ambos, centrais para o desenvolvimento humano. Além disso, como já evidenciado nessa pesquisa, Jean Piaget comprovou que a inteligência cresce da interação entre o cérebro e o mundo (conhecimento é fruto das experiências com o mundo, é uma operação que constrói os seus

\footnotetext{
${ }^{9}$ Sobre o tema recomenda-se a leitura dos trabalhos dos antropologistas e paleontologos Louis e Mary Laekey; Richard Leakey (filho); Donald Johanson e Sherwood Washburn, que apontam aprofunda interdependência entre a mão e o cérebro. O neurocirurgião canadense Wilder Penfield (1891 - 1976) também demonstrou em suas pesquisas a ligação íntima entre o cérebro e a mão no desenvolvimento humano, comprovada pelo mapa do cérebro desenvolvido por Penfield que mostra as proporções do cérebro dedicadas a controlar as diferentes partes do corpo, evidenciando que grande parte é destinada à mão. (KRISTIANEN; RASMUSSEN, 2015, p.92).
} 
objetivos). Assim, de um modo primário, como ensina RASMUSSEM (2015), o cérebro utiliza as mãos para construir seu próprio conhecimento de mundo.

O método LEGO Serious Play proporciona um ambiente de acolhimento, criatividade, liberdade de pensamento e desbloqueio de conhecimentos. Há uma perspectiva que torna esse desbloqueio ainda mais incrível: as pessoas não tem uma compreensão completa do que elas sabem. E a habilidade do método LSP para extrair conhecimento do inconsciente comprovou ser consideravelmente mais poderosa do que os criadores do método poderiam imaginar. $\mathrm{O}$ fato é que ao construir o pensamento e visão do mundo por meio das mãos, e por intermédio dos blocos LEGO, provoca-se uma conexão do tema-problema com o cérebro e a solução simplesmente aparece. Trata-se do conhecimento manual, aquele que sua mão conhece, mas seu cérebro não é completamente consciente sobre isso. (KRISTIANSEN; RASMUSSEN, 2015, p.89-95)

De fato, esse processo de construção com uso do pensamento concreto e da ligação entre mão e cérebro não se dá apenas por meio dos blocos LEGO, contudo, a variedade, flexibilidade, reutilização, modularidade e uso rápido do sistema de construção tornam as peças de LEGO superiores a qualquer material concreto conhecido, como evidenciou RASMUSSEN (20015, p.94).

Para Papert, o pensamento concreto (muito usado em crianças) é um modo complementar aos modos de reflexão mais formais e abstratos, e deve ser desenvolvido em qualquer estágio de aprendizagem (qualquer idade, cultura, idioma), pois é um meio valioso de pensamento e de construção de caminhos para o conhecimento, principalmente por desbloqueálos. O pensamento concreto é uma forma universal da razão humana e permite resultados mais rápidos e com mais confiança e compreensão do que representações abstratas e formais.

E é justamente com essa perspectiva que o método LSP se desenvolve, pautado no pensamento concreto e radiante (não linear e marcadamente emocional), com uma comunicação imagética significativa, desbloqueando novos conhecimentos e tornando o aprendizado memorável.

O método LSP pode e deve ser aplicado no ensino jurídico, pois garante a devida conexão entre teoria e prática, entre razão e emoção, bem como a devida interação entre os conhecimentos dos alunos e dos professores. Trata-se de uma técnica educacional interessada no aprendizado pela ação, na qual todos os participantes estão ativos, engajados e contribuem com o processo de aprendizagem, o que minimiza (praticamente anula) a dispersão, o 
desinteresse e o tédio dos discentes (grande problema do ensino jurídico do Brasil). Ademais, é uma metodologia de ensino em que os estudantes realizam a atividade e depois a estudam para melhorarem seu desempenho, acumulando, assim, experiências, motivação e o aperfeiçoamento da memória com fixação do conteúdo.

Dentre os inúmeros resultados, êxitos e benefícios do método LEGO Serious Play, KRISTIANSEM e RASMUSSEM (2015), bem como os autores deste artigo cientifico (por meio das experiências já realizadas com o LSP em suas salas de aulas nos cursos de graduação e de mestrado em Direito), evidenciam o seguinte.

O método LEGO Serious Play: a) coloca todos os participantes (alunos) no mesmo nível de jogo; b) mantém todos os discentes envolvidos continuamente e ativamente durante a atividade/aula; c) encoraja a revelar ideias autênticas; d) dificulta a influência de opiniões e perspectivas individuais sobre o assunto explorado; e) estimula o desenvolvimento participativo da comunicação; f) prioriza o auto-aprendizado, com o aluno no centro do processo de aprendizagem; g) estimula o aprendizado por ação; h) expande os horizontes, e proporciona a quebra de paradigmas convencionais; i) desbloqueia novos conhecimentos (inclusive os que as pessoas não sabem que possuem); j) auxilia os participantes a descontruírem o que seria uma situação altamente complexa (permite uma visão do todo); k) contribui para a concentração e interesse dos alunos; 1) o LSP é ainda mais eficiente quando o desafio é complexo e sem soluções óbvias (o que aumenta senso critico dos participantes); m) os estudantes acumulam experiências ao realizarem as atividades ativamente, fortalecendo a compreensão do conteúdo e alcançando a cognição efetiva; n) contribui para aumentar a inteligência coletiva da equipe, além de estimular o espírito de trabalho em equipe e interação social; o) o cérebro aprende melhor com as mãos e o LSP trabalha ativamente a conexão desses dois componentes centrais do desenvolvimento e aprendizado humano; p) é aplicável e funciona para todas as pessoas (tanto em crianças, quanto em adultos de qualquer faixa etária), bem como em qualquer idioma e cultura; q) é um método que trabalha não o que você já sabe conscientemente, pelo contrário, é desenvolvido para desbloquear novos conhecimentos e por isso é capaz de resultar em uma grande transformação da educação e cognição humana; r) permite a mudança de comportamento (quando os participantes estão sendo observados, eles normalmente irão conscientemente ou inconscientemente mudar o seu comportamento; s) o LSP prepara o aluno para saber se adaptar às situações inesperadas; t) o LSP gera valor para as pessoas e aumenta a confiança, a participação e o comprometimento de todos envolvidos; u) estimula o pensamento 
estratégico, aguça a criatividade, a imaginação e os sentidos, permitindo, assim, um pensamento inovador e concreto; v) permite que todos os sujeitos da educação (alunos, professores e instituição) experimentem e vivenciem o conhecimento; $x$ ) fortalece o ensino pautado na razão e na emoção, com uso da criatividade, sensibilidade e reflexões, maximizando o conhecimento e o desenvolvimento das pessoas, com resgate do ser Humano.

Por tudo isso, o LSP é uma metodologia altamente efetiva também para a (re)construção que o ensino jurídico brasileiro necessita. O LEGO Serious Play no Direito permite, da mesma maneira como em qualquer tema ou ciência, o desenvolvimento de todas as vantagens e resultados descritos acima.

Destaca-se que, com essa metodologia, na realidade, independentemente da idade ou do curso realizado pelo aluno (criança, jovem ou adulto), em virtude do pensamento radiante, da imaginação imagética, do desenvolvimento das atividades com as mãos e das associações realizadas pelo cérebro, o uso da metodologia do LSP favorece a comunicação, a criação de ideias, o pensamento sistêmico, reflexivo e estratégico, bem como o ensino e a aprendizagem de qualquer conhecimento, em qualquer ramo do saber ou ciência. Além disso, o uso do LSP torna o ensino e a aprendizagem mais fácil e prazerosa. É, pois, uma excelente ferramenta para inovar e estimular a educação e o aprendizado também nos cursos jurídicos.

Nesse sentido, não há dúvida de que a metodologia LSP pode e deve ser usada no ensino jurídico de graduação, bem como nos programas de pós-graduação stricto sensu, para que os mestrandos, futuros professores, possam estudar, entender e reconhecer essa metodologia como uma daquelas que realmente podem subverter a ordem tradicionalmente estabelecida e favorecer o florescer de um novo modelo (mental) de ensino, de pesquisa, de extensão, de interpretação e de aplicação do Direito.

\section{CONCLUSÕES}

Apesar de o ser humano ser psicologicamente refratário às mudanças, elas acontecem naturalmente, pois são inerentes à vida biológica. Além disso, a mudança é absolutamente necessária à inovação e à sobrevivência econômica, o que é absolutamente essencial em uma sociedade cada vez mais marcada pela lógica (normalmente cruel) do mercado e da eficiência. 
As pessoas, as instituições, as empresas e a história da humanidade estão marcadas por diversos momentos em que essas alterações de fato e de direito foram significativas e determinaram uma mudança de paradigma ideológico, cientifico (teórico) ou prático.

Tudo isso é absolutamente natural também no ensino, na pesquisa, na interpretação e na utilização (profissional) do Direito.

É evidente que os atuais alunos dos cursos jurídicos, pensam, convivem, interagem e se comunicam de uma forma diferente daquela que acontecia no início do século XIX, quando foram instalados os primeiros cursos jurídicos no Brasil.

O problema é que praticamente as mesmas metodologias usadas no século XIX são dominantes até hoje. No Brasil, o ensino jurídico ainda está calcado no pressuposto do conflito, da lei como a principal (única) fonte do Direito e do processo judicial como a mais importante forma de determinação da paz social.

Como restou demonstrado nesta pesquisa, é possível uma evolução metodológica no ensino do Direito, que facilite o desenvolvimento do pensamento sistêmico, a conexão (emocional e racional) entre docentes e discentes, a imposição de um novo modelo mental baseado na estruturação jurídica eficiente dos objetivos das pessoas (Análise Estratégica do Direito), sem o pressuposto necessário do conflito e/ou do processo judicial.

Tudo isso é possível de ser alcançado pelo uso de diversas teorias e metodologias de ensino diferentes, como são os casos do ensino baseado na solução de problemas (PBL), do construtivismo, do construcionismo, dentre outras.

A metodologia do LEGO Serious Play também pode e deve ser inserida nessa lista de novas possibilidades, não apenas voltadas para o ensino jurídico, mas também para a ideação, para a pesquisa e para utilização prática do Direito.

É por intermédio dessas metodologias inovadoras que se alcançará um ensino pautado na harmonia entre a razão e a emoção, capaz de motivar o corpo discente, de despertar o seu interesse para o aprendizado efetivo e proporcionar a mudança do modelo mental até então vigente. 


\section{REFERÊNCIAS}

ALFARO, Norman José Solórzano. Experiência jurídica, experiência de aprendizagem: algumas abordagens pedagógicas para gerar aprendizagens significativas no Direito. Meritum: Revista de Direito da Universidade FUMEC, Belo Horizonte, v. 8, n. 2, p. 411-440, jul. 2013.

ALVES, Rubem. A alegria de ensinar. 14 ${ }^{\mathrm{a}}$ ed.- Papirus Editora, 2000.

ALVES, Rubem. Educação dos sentidos e mais... .10 ed. - Campinas, SP: Verus Editora, 2014.

BECKER, Fernando. O que é construtivismo? In: BORJA, Amélia de et al. Construtivismo em revista. São Paulo: FDE, 1993. p. 87-93. (Série Idéias, 20).

BUZAN, Tony. Mapas Mentais: métodos criativos para estimular o raciocínio e usar ao máximo o potencial do seu cérebro. Rio de Janeiro: Sextante, 2009.

COLL, César et al. Los contenidos en la reforma: enseñanza y aprendizaje de los conceptos, procedimientos y actitudes. Madrid: Santillana, 1992.

FREIRE, Paulo. Pedagogia da autonomia: saberes necessários à prática educativa. 51. ed. São Paulo: Paz e Terra, 2015.

GABRICH, Frederico de Andrade. Análise Estratégica do Direito. Belo Horizonte: Universidade Fumec, 2010.

KRISTIANSEN, PER. Construindo um negócio melhor com a utilização do Método LEGO Serious Play. São Paulo: DVS editora, 2015.

LEGO Group. The science of lego serious play. 2002. Disponível em: www.seriousplay.com Acesso em 02 ago. 2016

MORIN, Edgar. Os sete saberes necessários à educação do futuro [livro eletrônico]. São Paulo: Cortez; Brasília: Unesco, 2013.

MUSSIO, Simone Cristina; VALIDÓRIO, Valéria Cristiane; MERLINI, Véra Maria Ferro. As novas tecnologias acopladas à educação: Reflexões sobre o ensino-aprendizagem no século XXI. Revista RETC, n. 14, p. 44-52, abr. 2014. Disponível em: <http://revistafatecjd.com.br/retc/index.php/RETC/article/view/127/pdf>. Acesso em: 3 ago. 2016.

RIBEIRO, Luis Roberto de Camargo. Aprendizagem baseada em problemas (PBL): uma experiência no ensino superior [livro eletrônico]. São Carlos: EdUFSCar, 2008.

ROSA, Sanny A. da. Construtivismo e mudança. 2. ed. São Paulo: Cortez, 1994.

BRASLAVSKY, Berta. Escola e alfabetização: uma perspectiva didática. São Paulo: UNESP, 1993. 
SASS, Odair. Construtivismo e Currículo. Artigo digital. Disponível em: http://www.crmariocovas.sp.gov.br/pdf/ideias_26_p087-103_c.pdf . Acesso em: 11 mar. 2016.

SENGE, Peter M. A quinta disciplina: arte e prática da organização que aprende. $24^{\mathrm{a}}$ edição. Rio de Janeiro: Best Seller, 2008. 